\title{
WOMEN ECONOMIC EMPOWERMENT IN PAKISTAN: A CRITICAL ANALYSIS OF LEGAL FRAMEWORK
}

\author{
Dr. Fozia Naseem \\ Assistant Professor, College of Law, GC University, Faisalabad \\ Dr. Farhana Nosheen \\ Assistant professor, Institute of Home Economics \& Food Sciences, \\ Government College University, Faisalabad, \\ Dr. Nazia Malik \\ Assistant Professor, Department of Sociology, GC University, Faisalabad
}

\begin{abstract}
Pakistan is a country that has been facing the biggest problem of gender inequality since its inception and has been considered one of the worst performers for decades, especially in terms of women's economic empowerment. Strategic analysis shows that this threat is the result of religious misrepresentation as well as many political, socio-economic and cultural barriers. Rendering to world economic forum report of 2018, Pakistan is classified 148th out of 149 countries. In Pakistan, women, who make up about half of the population, are deprived of basic services such as domestic violence, poverty, poor health, economic dependence and low literacy rates, with little difference between metropolitan and rural life. At the same time, this research should carefully address this issue and point out that legal reforms are necessary and indispensable for the participation of women in the economic development of the country. This will be a first stride to provide objective measure of how specific regulations, implementation and protection of inheritance of property right affect women's inclusive participation in economic development. The study is correlated to new index introduced by WBL2019 which is structured around eight indicators that encompass different stages of women's working life, provide essential grounds for economic standing of women, the particular emphasis will be on seventh indicator that is managing assets that involves ownership and inheritance of property.
\end{abstract}

Keywords: Economic empowerment, Legal reforms, Property rights, Inclusive participation, WBL

\section{INTRODUCTION}

It is an undeniable fact that female vary in comparison to men folk in their social prestige and that these dissimilarities comprise of disproportionate, inadequate authority associations between the genders, "women's empowerment" signifies the practice of increasing women's capacity to rheostat over the deliberate life ranges, which influence their approach towards the chances that permit them in comprehending their capabilities. The empowerment of women; financially, politically, and in sociocultural context defies the patriarchal culture of Pakistan to counter women's subservience and ostracism for the betterment of women's standard of life. The process of empowering someone remarks on the previous incapability of that person to do so. It can be described as the procedure of enablement in the social milieu involves that power is donated to the feeble from the influential objects in the society by permitting the feeble and the ostracized to have access to the resources they need to discover their own destinies (Sinha, 2005). This definition highlights the existing problem of economically dependent women who are completely dependent on the male head of the family.

Probing the issue of empowerment, the constitutional and customary laws play a significant role. It is a fact that the constitution of Pakistan identifies the law of equality for all citizens and the right to equal security of the law principally; the constitution of Pakistan discourages any kind of discrimination on the basis of gender, demands the state to take necessary steps to ensure it. One practical step is the legislative measure of quota system for female to 
increase their participation in policy making, this effort is patent at significant degree around the world (Ali \& Akhtar, 2012). The persistence of this allocation is to minimize women's isolation in political field and encourage their participation in politics. There are other elements that influence constitutional law i.e., a customary law, which particularly performs a significant part in case of deficiency of any constituted/written law. Economic empowerment is indispensable for the progress of any state as it is a step to acknowledge the involvement, abilities and contribution of female in growth process and to make them take a fairer distribution of the benefits of that development. Financial empowerment improves women's access to financial resources and chances in employment, economic services, property and other fruitful resources.

\section{Islamic Background}

Most of the times, economic discrepancy in Muslim countries is attributed to religion while ignoring the reality that the first ever Muslim woman Hazrat Khadija Tul Kubra was the business woman. Her decorum and accuracy was irresistibly venerable with her well reputed honesty of business in the male ruled society of that time. She acquired the business after the demise of her father that also provide us a model for the law of inheritance of property and business to a woman without any gender judgment prevalent at that time, and still had its control deep rooted in patriarchal cultures. Her father was a popular trader in Quraish tribes of Mecca. After her father's death, she acquired the responsibility of trading goods from main business hubs of that period, Mecca to Syria and Yemen. Her trade was loftier than all of Quraish trades combined with highly praised honesty of business dealings and high quality goods.

It's noteworthy that this prestigious lady of marvelous character 'Khadijah R.A' was a remarkable person, having high degree of business and expertise at home making, Khadijah donated much charity to help poor people in need. By her determination, understanding and helping, Khadijah Al Kubra proved herself as a great acquaintance, loving mother and an exemplary character of all times (Saba \& Bari, 2020). In Islamic countries; social constraints, political dogmas, patriarchal culture, illiteracy and unawareness of women about their rights, and religious misrepresentation create impediments in the route to economic independence of women. It is common observation that females are disadvantaged of their fundamental right of inheritance, the male heirs keep getting commercial benefits of the property linger on the process of distribution as in Pakistan there is no law that restrict them to infringe the economic empowerment of the female of their family. This practice is common among highly educated and elite class without any percipience from illiterate and lower middle class. Women who are already clutched by social constraints, if take courage to get legal support, the justice is delayed that much that sometimes the petitioner die prior to enjoy the fruits of that justice. Our legal history is replete with such cases although Pakistan, being an Islamic republic, deals with matters of inheritance according to the Sharia law which permits women the right to inherit property.

Islam acknowledged women's share of inheritance in the time when it was against the prevalent custom and women were often treated as commodity to be inherited and handed over as assets. It is revealed in the Quran, "O ye who have faith in it is not permitted to you to forcibly inherit the women (of your departed kinsmen)." Islam also assured women that their property, they acquired through inheritance or personal effort, is entirely their own and the male custodian has no prerogative over it. The Holy Quran is the main source of guidance for all Muslims. It is combined with actions and sayings of the Holy Prophet (SAW) as well as other techniques of Islamic juristic cognitive abilities, e.g., consensus and analogical clarification, where required. In case of the inheritance, the Holy Quran not only declares inheritance to be a right of every human being, it also defines shares in each case. Matters of legacy have been meticulously described in various chapters of Surahe al-Baqarah, Surahe al-Maidah and Surahe An-Nisa.

The priority here is leaving one's family comfortable: Saad bin Khula narrates that when Holy Prophet PBUH came to visit him, at that time he was on his death bed, afflicted with a sickness. I said, "O Allah's apostle! I have much property and no successor except my single daughter. Shall I give two-thirds of my property in donations?" He said, "No." I said, "Half of it?" He (SAW) said, "No." I said, "One-third of it?" He (SAW) said, "You may do so though onethird is also too much, for it is better for you to leave your off-spring wealthy than to leave them poor, asking others for help. And whatever you spend (for Allah's sake), you will be compensated 
for it, even for a morsel of food which you may put in the mouth of your wife."

Thus, we can observe a visible revolution in the life of the women of that time that their due share is provided to them without any discrimination. By taking directions from Islamic laws and history of Islamic women, we can observe a change in the Muslim world especially in the new millennium, this awareness is increasing among Muslim ladies, and economic empowerment of women increased in last 15 years.

Most Muslims live in thirty developing markets in which their population is in mainstream that comprises world's one fifth population and $12 \%$ of worlds GDP. These include countries with high per capita incomes including UAE, Kuwait, Qatar and Saudi Arabia; the countries with upper middle economies such as Tunisia, Jordan, Iran, Turkey and Malaysia; and lower middle income economies such as Tajikistan, Bangladesh, Egypt, Indonesia, Pakistan and Morocco (Zahidi, 2021).

Employed women at present epitomize thirty percent of the 450 million females in markets of the countries with Muslim-majority. Labor force involvement rates differ widely; Saudi Arabia (21\%), Pakistan (26\%), Turkey (33\%), UAE (42\%), Malaysia \& Indonesia (53\%) and Kazakhstan (74\%), but these rates are rising quicker for females as compared to male in almost all economies with Muslim majority. It is also attention-grabbing fact that women in Muslim world are now participating in economic improvement of their countries by attaining scientific and technological positions in this ever-changing world of progression and dexterity. According to an estimate, the working class of women can add billions of dollars in Muslim world economy, because the women of modern world are numerically connected as the modern world has opened up new horizon in economic fields for them. It ranges from education, health, IT, fashion, designing, catering, beauty industry, agricultural fields to political participation, and managing and administrating high positions in multinational companies and business enterprises. In the Middle East, if females labor contribution increased to its' full prospective by 2025 , the region's GDP would increase to 47\%, according to McKinsey (Desvaux et al., 2017).

Just after this millennium, there can be an increase up to $11 \%$, if women participation is improved in this region to make it comparable to the best performing countries of this region, there was around fifty percent increase in the numbers of women participating in the emerging markets as their number rose up from 100 million to 150 million in just 15 years.

\section{Difference between Rhetoric and Perception}

While discovering truth of female liberation, ground realities vary from what is appraised as the "rhetoric between theory and practice" seems to be very wide. Expressions such as new age females and female of material are just arguments in books (Bhattachar, Priyadarshani, Kumar \& Rai, 2016). Deceptively, females might be bestowed authorization but the ground reality transforms very infrequently. In fact, individuality and sufficient autonomy are ardent terms. On real facts, the picture is quite different, specifically; women who are always considerate, forgoing and loving for her family is supposed to abandon her property right for male members of her family out of love, social pressures and traditional constraints (Miller, Barber \& Schulz, 2017). Social order is not bisected on the capabilities of individuals.

Rules does not seem to be unbiased term in this context rather, "issues of sexuality are at the heart of the power mechanism in the modern society". In human cultures, different professions are deemed as unattractive for females as they are unpleasant to them. The constitution of Pakistan inculcates equal rights for females including right to own and control land. Pakistan has also established several worldwide contracts boosting gender equivalence such as CEDAW and ILO essential agreement on equal payment for females. However, the Constitution deals no straight provision on females' right other than contracts and values of strategy to guarantee justice without perception.

It is irrefutable point that females are deprived of their rights to obtain land awards, land legacy and sometimes compelled to surrender their land rights in errand of the male members of their children. Females doesn't get any of Pakistan's land reform and land reallocation activities. Since this ruling by the court, all land reallocation is done through watering state land and providing land titles. In 2008, the Government of Sindh led by the People's Party set up a program to reallocate unrefined lands mainly to females (Khan, 2021). 
Haq Bakhshwana is quite a common practice in all over Pakistan especially in KPK and Sindh. Women are deprived of their right of getting wedded, or they were married to Qur'an to stop relocation of assets. It is unacceptable for people to let women own any property even if she is the only living heir, assets will handover to any second relative than her. Females will be reflected as assets themselves and they are taken over by other males. Women do not continue their legacy without support of some male member ancestral care. If they do it without any assistance, they will be ostracized, or blamed as Kari and killed in the name of honor killing in Sindh (Khan, 2021).

Restriction of flexible degrees will obstruct them from handling terrestrial matters. This seclusion will contain measures as covering, privacy, restricted motion and avoidance from intermingling with outsiders or in open. Purdah is considered a critical reason for why women could not manage land, told by male respondents in one survey. For women in medicine and law, that gap is even larger (around 70 cents for every dollar). According to a research conducted by wealth management company UBS Global in March 2019, more than 50\% of women prefer to leave long-term financial planning to their spouses. Almost $82 \%$ of women are of the view that their spouse is better in planning financial issues (Duflo, 2012).

The life of women in Pakistan is organized by male-controlled society. Such societies do not provide equal rights to women. Conventionally, a Pakistani female develops subordinate position even in her family. Dissimilarities exist between females and males in health, education, income chances, employment, personal security, control over assets and participation in the politics. Pakistan is amid those societies that have extensive gender disparity and observe huge difference amongst females and males in all matters of life (UNICEF, 2006).

The world economic forum suggests that five areas need to be focused for attaining gender parity:

- $\quad$ Medical sector

- Educational accomplishment

- Welfare of women

- Political participation

- $\quad$ Economic empowerment

\section{Impediments of women economic empowerment in Pakistan}

It is observed that women and the girls are deprived of their basic rights because of traditional, cultural, socio-economic and religious constraints. In Pakistan, economic empowerment of women demands certain urgent steps to be taken to eliminate root causes along with some legal reforms to be introduced in law to encourage equal contribution of women in workforce with improvement in the implementation mechanism so that the rights guaranteed by law can be protected and enjoyed by the deprived entity. Conventionally, in patriarchal culture, male chauvinism guarantees female subordination through their financial dependence on the male head of the family that has reduced the rule of women to their reproductive potential, and property to the male who occupies central position in the social fabric of a society. This study is correlated to the new index introduced by women business and law 2019, based on eight indicators that encompass different stages of a life of a working woman. The main field of study will scrutinize how far existing laws in Pakistan and their implementation mechanism safeguard economic empowerment of women. 


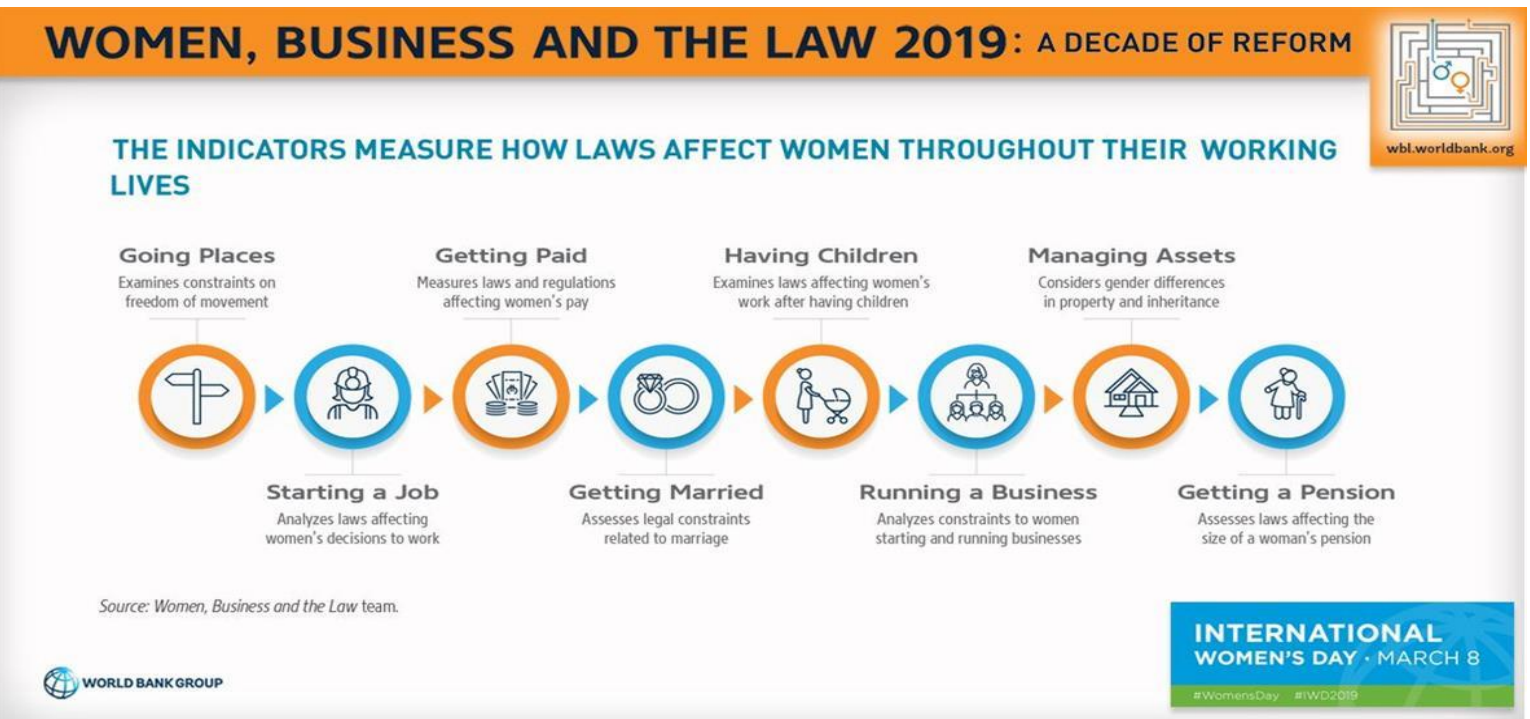

Fig. 1.1: Indicators of measuring the laws affecting women (Iqbal, 2018)

$1^{\text {st }}$ indicator is going places that helps us to evaluate how far women of our region are free to move, 2nd indicator deals with starting a job that unveil the decision making power of women to start a job, 3rd indicator analyzes the laws regulating women pay and gender pay differences, 4th indicator helps us to examine the problem faced by married women to continue her job, 5th indicator considers women work after having children and the facilities of day care centers and provision of maternity and paternity leaves, 6th indicator helps us to enumerate barriers in initiating a business, 7th indicator deals with managing asset that highlights the gender differences in inheritance of property, and 8th indicator encompasses that how far women succeed in getting pension in a country. The main consideration of this study is 7 th indicator.

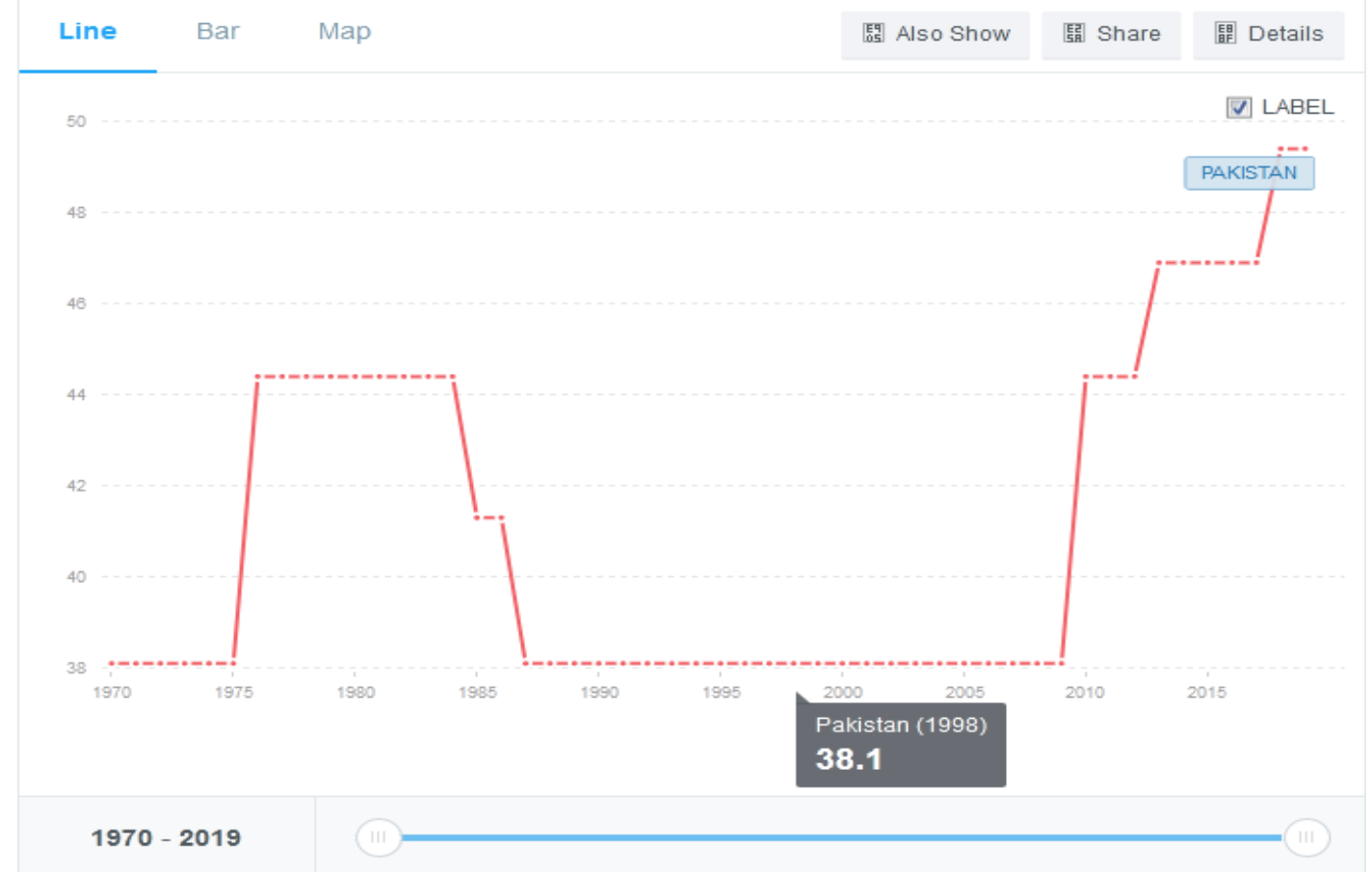

Fig. 1.2: Bleak picture of economic empowerment of women from 1970 to 2019.

It is observed that norms and ethnicities executes a considerable role in defining the position of women in Pakistan in different domains of life as numerous practices are deliberate desecrations of constitutional and Islamic laws and are evidently unfavorable to women's wellbeing. However, in an atmosphere where permissible securities are either absent or not implemented, some cultural practices and customary laws play their significant role to fill the gap. This situation is recognized in various other circumstances in which customary institutes "step into the breach" to fulfill the space missing by lacking or unimplemented legal securities, more 
common in rural life.

It is unavoidable that if a woman need to be financially self-determining and informally active, her prestige and resilience prerequisite to be elevated first, at that time she requires to be informed of her position in the society. The author of the "suggested Measures for the Empowerment of Woman" enumerates seven key points that are indispensable to achieve the desired objective (Meenu, 2007).

- $\quad$ Creating awareness among women about their rights

- Improvement in their quality of living

- $\quad$ Equality in the ownership of productive resources

- $\quad$ Better health facility to the women and their children

- Increasing education level and literacy rate

- $\quad$ Better liaison in the field of commerce and economics

- $\quad$ Accomplishment of self-confidence, self-esteem and self-reliance (Meenu, 2007).

Besides, enlightenment, occupation, interaction with external world, character improvement, financial individuality, utilitarian and lawful sustenance, elevation of women annexes and supporters are the preconditions for the enablement of women empowerment. These social developments are essential to be taken to give sustainable power to women. Terminologies such as "new age women" and "woman of substance" are mere argumentative in paperwork. Apparently, women might be conferred empowerment, but empowering women in its true spirit is a far cry. Actually, individuality and sufficient self-confidence are 'idealistic terms'. Practically, women who are always thoughtful, sacrificing and caring for their family usually abandon their rights. Women possession of productive resources is a difficult task in Pakistan despite of women's permissible privileges to acquire the inherited property from their relatives, it's precisely occasional that women have possession and control over resources. A micro level assessment of 1,000 rural households conducted in 1995 in Punjab established that only 36 women retained land in their personal name, whereas only 9 of them had authority over it (Rashid \& Ejaz, 2019). Correspondingly, recognized commercial institutes do not accommodate women financial needs owing to the fundamental assumption of women's part in the generative domain.

In spite of economic dependency, women in Pakistan are also suffering from occupational sexism and male chauvinism that signifies discrimination at the work place and wage gap. The Economic Cooperation and Development Organisation estimated in 2008 that while female work rates have stretched, gender employment and pay disparities have declined on average almost everywhere, women still have a 20 percent lower chance of getting jobs and are paying 17 percent less than men (Anjum \& Ming, 2018).

Therefore, performance pressure, social isolation and role capsulation create real hindrance in economic empowerment of a woman that can unchain a woman from the vicious cycle of dependency. It is observed that the ratio of unemployed women is much higher as compared to unemployed men in Pakistan, which leads to economic disasters and given less privilege by society. Gender pay gap in average gross hourly as per Eurostate, 2014 Gender inequality index Value 0.536(2014), ranked Pakistan 121st out of 157, while Global Gender Gap Index Value 0.556(2016) ranked Pakistan 143rd out of 149. 


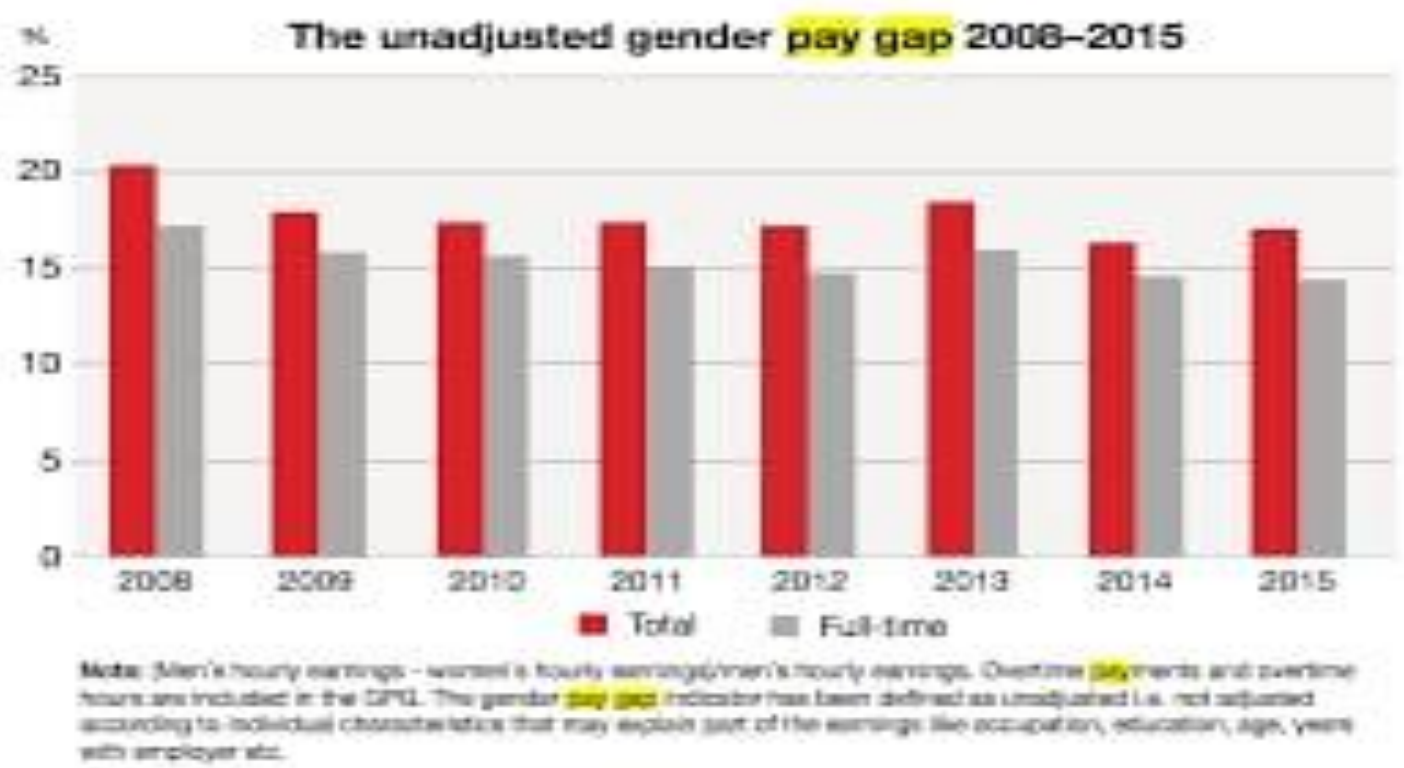

Fig. 1.3: Gender Pay Gap 2006-2015

Women economic empowerment is also good for business as it is observed that women participation in an organizational management increases its quality of work. Companies of three or more women in senior management departments are expected to rank higher in all corporate efficiency measurements. One-third of women are involved in agriculture, including forestry and fisheries. There is a significant difference in various regions of the world, the proportion of women in high-middle-income countries is $9.5 \%$, in high-income countries is $2.6 \%$, while agriculture is the largest employment sector in low-income countries (Sohail, 2014).

Women are responsible for water collection in 80 percent of rural households, they are responsible for fuel and food supply in households, and directly affected by the scarcity of water and lack of safe reliable, affordable and clean energy. Indoor air pollution from using combustive fuels for household energy caused 4.3 million deaths in 2012 with women and girls accounting for every 6 out of 10. Similarly, they are the worst victims of environmental degradation and climate change are women and children as most of the natural resources are grabbed for commercial purposes in urban areas. Pakistani women are imprisoned in a vicious circle of dependency and subservience due to their lower socio-economic, and political status in society.

\section{The Condition of Literacy of Women in Pakistan}

Pakistan is amongst those states which have the world's lowliest savvy rate, which is the core cause for its less agronomic development and sedentary budget. It is a reality that Pakistan's rate of literacy differs province-wise and in comparison to some other Asian countries including Bhutan, Nepal, Bangladesh and India, Pakistan has poor education sector, which is the most important part for the attainment and growth of any nation, which has led to rank Pakistan113 in a total of 120 countries (World Bank, 2006)

Moreover, the standard of literacy in Pakistan is the competency to read and write name. This is ridiculous enough that in this age of technology, advanced education is ignored in our country and our government is spending only $2 \%$ of its total GDP on Education (Ali, Bashir \& Kiani, 2015). This is key issue for the females lagging behind in economic growth, as well as another upsetting state of matters. Without devotion and developments to the education system, Pakistan will face even greater difficulties. The current condition of woman literacy rate is given in statistical data. 


\section{Pakistan: Literacy rate from 2006 to 2017, total and by gender}

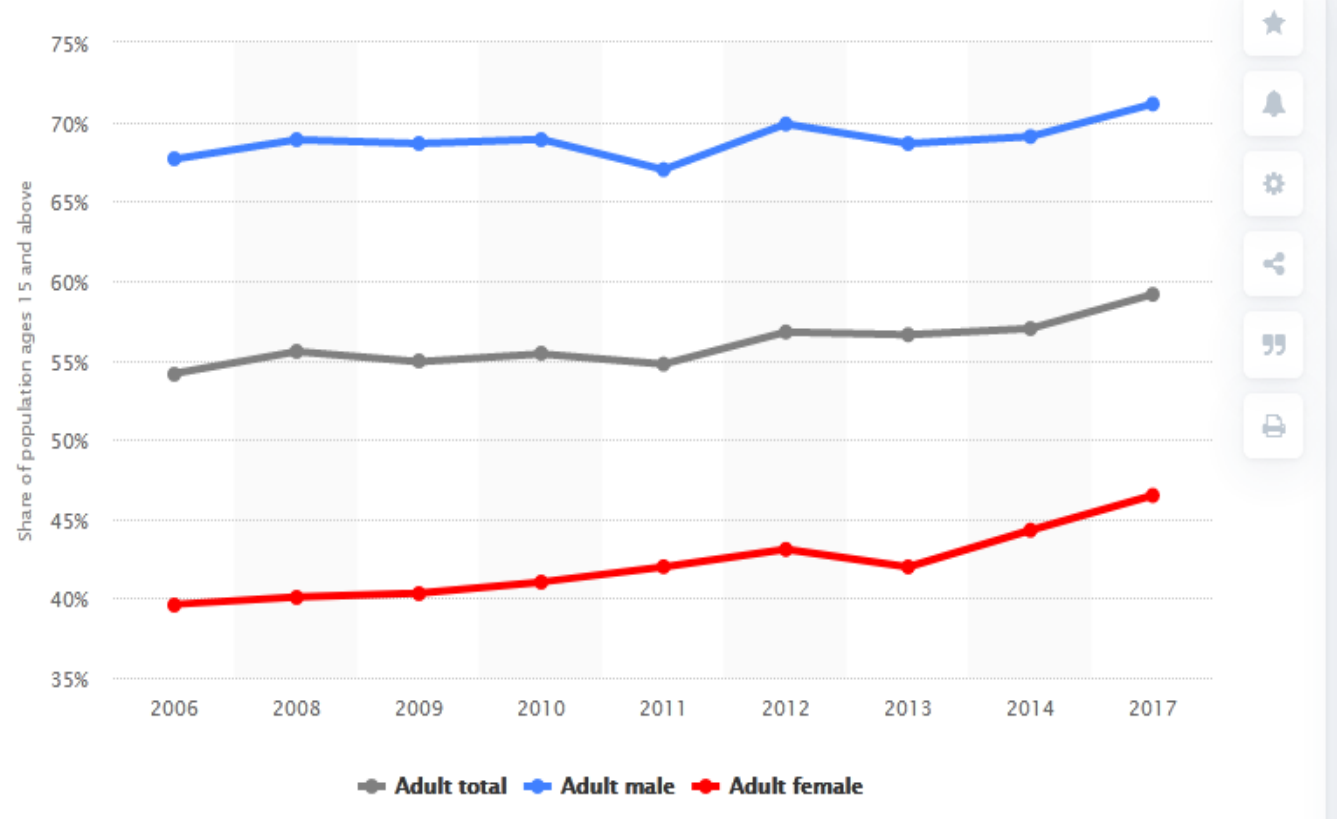

Fig. 2.1: Literacy Rate in Pakistan

\section{Female Subordination}

We live in an incompetent society, where women are thought of as naturally obedient to and dependent on the other half, men. In spite of substantial advances in the 20th century, hypocrite philosophy still covers our everyday lives and females are conventionally subsidiary to males in their more general public roles. The reasons behind this male-controlled culture is either patriarchy itself or an industrialist mode of production that leads to female subservience in our society. We are usually moving in a channel recklessly following the standard and cultural values to attain the appraisal and acceptance from our society. We are frightened to challenge the accepted styles for our plain existence. The one predominant norm is that the male dominance and female subordination cannot be challenged. Women are considered and termed as better halves of their husbands, they are truly alleged as just a possession of their spouses, and snubbed to have equal rights and chances which men in the society are enjoying. In my approach, they are not only better halves of their spouses, but are also making half of the population of the country so their causative role must be recognized.

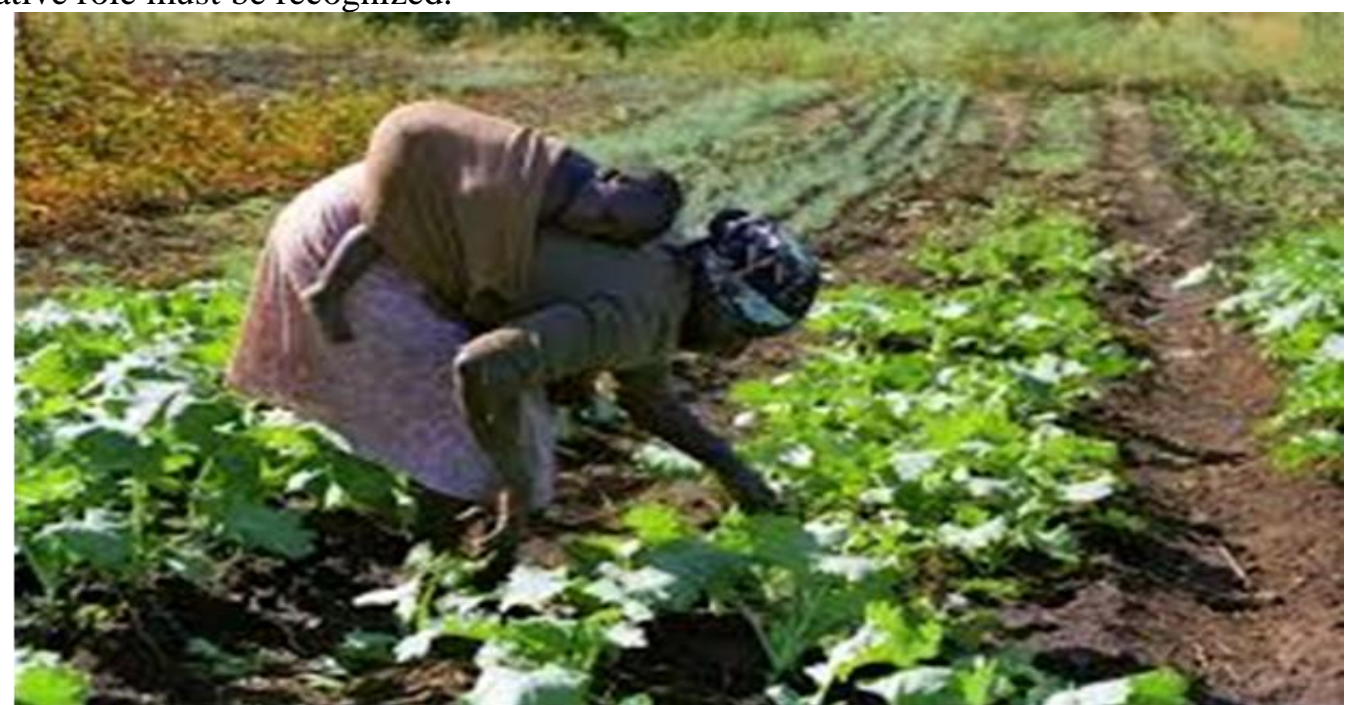

Fig. 2.2: Female working as labor along with her child 


\section{Economic Dependency}

The UN Committee on public, economic and customary rights renowned that more than $73 \%$ of labors, majority of them women, are in the casual economy with no labor or social defense. The Committee frazzled on Pakistan to address the gender pay gap which rose from $34 \%$ in 2008 to $39 \%$ in 2015. They further stated that satisfactory steps must be taken to decrease the gap between girls and boys in enrollment for education (Kambarami, 2006). Around 58\% of households were food uncertain according to National Nutrition Survey. This economic uncertainty and food insecurity increased violence in the sole bread earners of the family that ultimately leads to communal corruptions. One antagonistic form of which is honor killing that not only helps to reduce economic burden but also give satisfaction to the male arrogance (Muhammad, 2021).

\section{Occupational Discrimination and Sexual Harassment at Workplace}

Along with economic dependency, females in Pakistan are also distress from professional bigotry and male prejudice that indicates discernment at the work place and remuneration gap. In 2008, the organization for economic cooperation and development defined that while woman service rates have extended, gender employment and salary gaps have tightened nearly everywhere, and on average, women have $20 \%$ less chance to have occupations and are paid $17 \%$ less than males. Therefore, performance pressure, social separation and role capsulation create hindrance in economic authorization of females that can unchain women from the rancorous cycle of reliance (Muhammad, 2021).

\section{Labor force participation rate has risen for women, fallen for men}

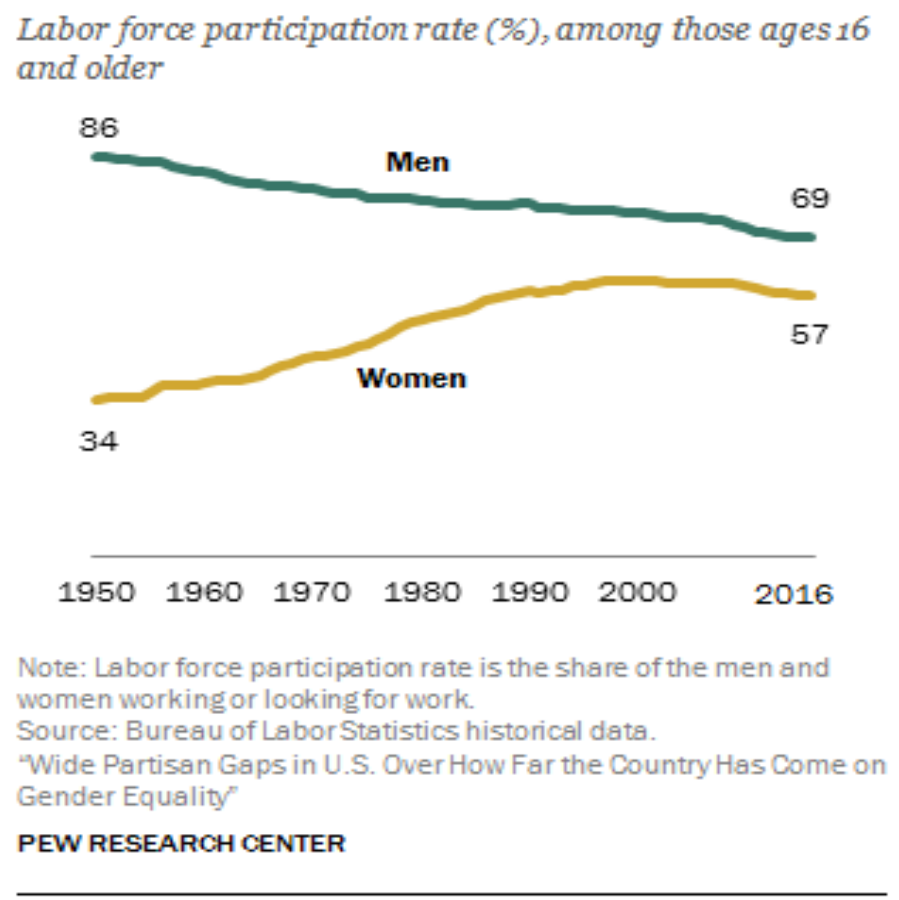

Fig. 2.3: Labor force participation of women

Begum Sadaquat and Sheikh (2011) revealed in their study that the economic crisis is the result of less privileges given by society to the women, resultantly, the ratio of unemployed women is much greater than the unemployed men in Pakistan.

\section{Poverty}

The condition of poverty reduction is not constant as it is deteriorated by many factors including; the corruption of different Governments in their reign, wrong policies, unnecessary priorities, money laundering, investment of leaders outside Pakistan, lack of foreign investment, poor strategies to curb this demon, and above all ignoring women inclusive contribution in economic uplift of the country. This bleak situation prevailing in the country is termed as "poverty bomb" in 
an assessment of the government of Pakistan by the international Monetary fund IMF in 2001, indicating that government is preparing the Interim Poverty.

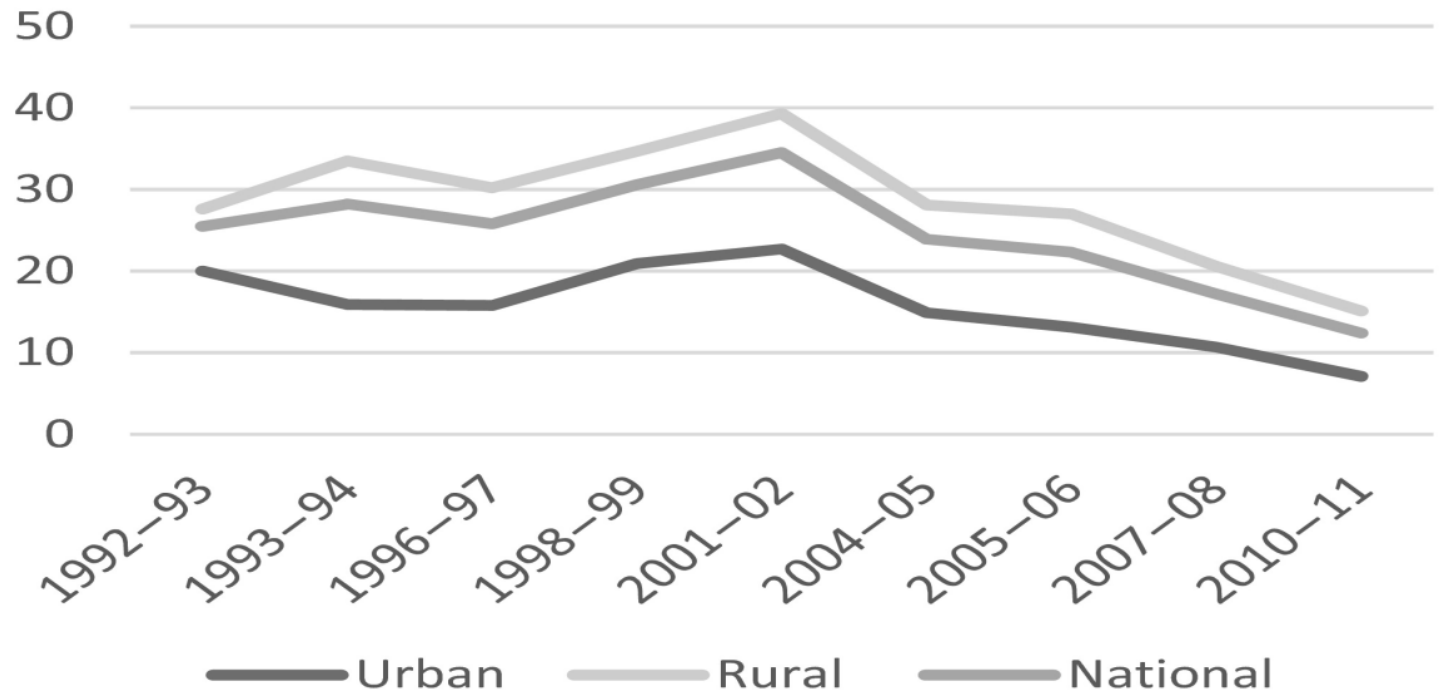

Fig. 2.4: Household empowerment is the key to eradicate poverty in Pakistan

This economic instability and food insecurity increased aggression among the sole bread earners of the family that ultimately leads to many social crimes. Lack of professional skills and lack of scientific and technological education is one of the main causes of prevailing economic disparity in Pakistan.

Girls are deprived of basic education which made them unable to cope with ever changing trends of modern age. Moreover, increasing mechanization has worsened the situation. The women, who were engaged in household labour as domestic helpers, are main victims of this mechanization. In agricultural fields, women collected wheat or rice as source of food for whole year as their wages. Now, plantation of paddy and harvesting of wheat and other crops made them deprived of this labour in agriculture communes because of use of threshers and other mechanical instruments.

\section{Economic Empowerment of Women and Sustainable Development}

Economic empowerment of women paves a new path for gender equality that in turn will lead to poverty eradication and inclusive economic growth. Women working in business community, health department, education sectors, in urban areas or passing through arduous journey of rural life from dawn to dusk looking after their toddlers, performing house hold chores, rearing their livestock or contributing in cottage industry make tremendous contribution to the world economy, but still this is a dilemma of this world that they are the main sufferer of poverty as almost one third of the poverty stricken are the women, they are denied access to owning property and loans, or making economic policies and social development plans.

Even if the balance of the available resources is disturbed, ignoring sustainable development goals made women the main sufferer of this plight. All the goals of sustainable development are integrated and interconnected closely with goal of gender equality, which is inevitable in attaining development goals of promoting full and productive employment and decent work for all to end poverty and provide food and health security through reducing inequality (Naz, Ashraf \& Iqbal, 2020).

\section{Delayed Justice}

Delayed justice is no justice, it is undeniable fact. The history in our judicial system is replete with such cases where plaintiff in pursuit of justice faces much problems, and the judicial procedure is that laborious and slow that the petitioner no longer remained in this world to see the fruit of his struggle. The matters related to the right of inheritance of property is no exception and the women mostly are unaware of their legal rights, they are deprived of their rights through Haqbakhshwana, Quran say nikah, swara, marriages with cousins without any compatibility, karokari and honour killing are other indirect means to save property by the dominant male heads 
of this patriarchal society.

The women face so many social constraints like dependence on brothers as source of support and strength even after their marriage. In case of claiming property right, the first hindrance is social reproach and reprimanding of family heads of forgetting all favours of male heirs in arranging dowry and other social issues, so claiming property right is a heinous crime in social context of Pakistani culture. The women are supposed to keep silent till the time the male heirs decided to divide the property. It is a common observation in current scenario that the male heirs keep on enjoying the commercial benefits of the property using delaying tactics for years and years with a plea that we don't want to spoil the honor of the father by dividing property, so they continue to use land and rents for commercial benefits, which if calculated is more than the financial value of that property. For example, if the property is on the commercial market, the rent collected per month is lets supposed 50,000 and the property is not divided for 20 years after the demise of the deceased, 50,000 in 20 years are estimated 120,00,000 Pakistani rupees. There is no mechanism for the women to claim for that amount produced by commercial benefits. According to a survey conducted in January 2017 by a non-governmental organization AGHS. It is reported that the $80 \%$ women in Pakistan are not getting their legal share in their inherited property.

The grave situation of gender discrimination prevailing in Pakistan correlates the miserable position of women before the promulgation of Islam. Pakistan is one of a country which appeared on the map of the world in the name of religion. Islam is the religion that gives most prestigious position and distinctive privileges to women as compared to the other religions. All the epistemologies that Islam imposes restrictions on the mobility, running a business or getting education of women is just a delusion or unawareness of the Islamic teaching or anti-Islamic propaganda.

\section{CONCLUSION}

Revolutionary change in perception is required to bring women out of inferiority complex along with major changes in social and economic order to bring transformation in our society. It is observed that to bring structural changes, women participation in decision making is equally important. Women's presence in power organizations is crucial for substantive changes in the improvement strategies and packages that would bring a shift in women's contribution in the society. The economic independence will also curb established violence against women at the family, community, and state levels that is used as a mechanism to ensure their submission to acknowledge status of women. Patriarchal culture and violence directly influence the women claim of property right in Pakistan. All these factors including economic dependency, ill treatment of women and the refusal to get due share in property are detrimental for status of women in society (Rubab \& Ahmed, 2018).

Paradoxically, it is observed that a lot of verbal attention has been given to gender matters at the nationwide level. Pakistan has ratified a number of obligations at national and international platforms to confirm gender equality at all levels. Nevertheless, there is an extensive breach in promise and execution. The inducement of the State to interpret its obligations to gender equality into tangible veracity is the great trial confronted by Pakistani ladies.

\section{REFERENCES}

Ali, A. A. \& Akhtar, M. J. (2012). Empowerment and political mobilization of women in Pakistan: A descriptive discourse of perspectives. Pakistan Journal of Social Sciences, 32(1), 221-228.

Ali, T. M., Bashir, T. \& Kiani, A. K. (2015). Assessment of technological capabilities of OIC countries. Science, Technology and Society, 20(1), 114-131.

Anjum, A., \& Ming, X. (2018). Combating toxic workplace environment: An empirical study in the context of Pakistan. Journal of Modelling in Management.

Bhattacharya, P., Priyadarshani, S., Kumar, D., \& Rai, I. D. (2016). Bibliography on microflora (lichens, fungi and bacteria) of the Indian Himalayan Region. Bibliography on the Fauna and Micro flora of the Indian Himalayan Region, 17, 264. 
Desvaux, G., Devillard, S., Labaye, E., Sancier-Sultan, S., Kossoff, C., de Zelicourt, A., \& Barton, D. (2017). Women Matter, Time to Accelerate: Ten Years of Insights Into Gender Diversity. McKinsey.

Duflo, E. (2012). Women empowerment and economic development. Journal of Economic literature, 50(4), 1061.

Iqbal, S. (2018). Women, Business, and the Law 2018. Washington, DC: World Bank Group

Kambarami, M. (2006). Femininity, sexuality and culture: Patriarchy and female subordination in Zimbabwe. South Africa: ARSRC.

Khan, A. (2021). Supporting Women's Empowerment in Pakistan: Lessons for Donors., Institute of Development Studies, 6(21), 67.

Meenu, A. (2007). Women Empowerment-Today's Vision for Tomorrow's Mission. Mahamaya Publishing House.

Miller, W. B., Barber, J.S., \& Schulz, P. (2017). Do perceptions of their partners' childbearing desires affect young women's pregnancy risk? Further study of ambivalence. Population studies, 71(1), 101-116.

Muhammad, F., Bano, K., Muhammad, K., \& Baig, T. (2021). Women empowerment in Pakistan: assessing the socio-economic determinants. Studies of Applied Economics, 39(3), 65.

Naz, A., Ashraf, F., \& Iqbal, S. (2020). The Relationship between Higher Education and Women Empowerment in Pakistan. UMT Education Review, 3(2), 65-84.

Rashid, A. G., \& Ejaz, L. (2019). Interest free micro credit loans: Pakistani female entrepreneurs. Journal of Islamic Marketing, 14(12), 73.

Saba, I., \& Bari, K. (2020). The Role of Women in Business and the Life of Khadija. In economic empowerment of women in the Islamic world: Theory and Practice (pp. 85-100).

Sinha, D. (2005). Empowering women; A catalyst in social development. New Delhi: Serials Publications, 2, 135.

Sohail, M. (2014). Women empowerment and economic development-an exploratory study in Pakistan. Journal of Business Studies Quarterly, 5(4), 210.

World Bank. (2006). The World Bank Annual Report 2006. The World Bank. 67.

Zahidi, S., (2021). Working Muslim women are a trillion-dollar market. [online] World Economic Forum. Retrieved from: https://www.weforum.org/agenda/2018/05/muslim-womentrillion-dollar-market-saadia-zahidi/. 